\title{
The evaluation of music therapy process in the intersubjective perspective: the music therapy rating scale. A pilot study
}

This article was published in the following Dove Press journal:

Pragmatic and Observational Research

| August 201 I

Number of times this article has been viewed

\section{A Raglio' \\ D Traficante ${ }^{2}$ \\ O Oasi ${ }^{3}$}

'Sospiro Foundation, Cremona, Italy; 2Education Technologies Research

Center (CRTI), ${ }^{3}$ Department of Psychology, Catholic University of the Sacred Heart, Milan, Italy
Correspondence: Alfredo Raglio Sospiro Foundation, Piazza Libertà, 2-26048, Sospiro (Cremona), Italy

Tel +390372620264

Email raglioa@tin.it

\begin{abstract}
This study presents a tool (Music Therapy Rating Scale [MTRS]) to evaluate the progression of the relationship between the patient and the therapist during music therapy sessions. The rating scale was developed from an intersubjective framework and from an improvisational music therapy technique. It mainly consists of two behavioral classes: non-verbal communication (NVC) and sonorous-musical communication (SMC). Five levels for each class are given (from 0 to 4). Every 15 seconds, two sets of two music therapists coded the behaviors in seven sessions with different patients. The patients were seven children (four males; three females) aged 3-10 years (mean age $=6.28$ ), diagnosed with Pervasive Developmental Disorder. The reliability indices were computed and there was a substantial agreement in the assessments of the video raters (non-verbal relationship: $\rho=0.70$; sonorous-musical relationship: $\rho=0.77$ ). A digital output of the program to use the MTRS is presented and clinical implications are discussed.
\end{abstract}

Keywords: music therapy, intersubjective approach, affect attunement, process assessment

\section{Introduction}

In psychotherapy practice, the evaluation of the process is one of the most important areas in research. ${ }^{1-3}$ The evaluation of the process is very important also in the field of music therapy: it consists of determining the changes that are happening during music therapy sessions and over the whole treatment, starting from a theoretical background. ${ }^{4}$

As in our previous research, ${ }^{5,6}$ the starting point of our work is both psychoanalytic and music therapeutic studies. In particular we refer to the intersubjective approach, ${ }^{7-10}$ and to the active music therapy technique that is based on the use of sonorous-musical improvisation in a non-verbal context. This music therapy approach intends to co-create a sonorous dialog between the patient and the music therapist by means of musical instruments, prevalently rhythmic and melodic ones of easy use. The musical exchanges give rise to shared emotions: according to Stern, dance and music are examples of the expression of the vitality affects ${ }^{7}$ and contribute to determine the conditions of the affect attunement, ${ }^{7}$ on which a primitive sense of Self is built on. In this way, music therapy allows an organizational process and a coregulation of emotional components into the couple at work in the session. ${ }^{8-10}$

The rating scale is a way to quantify both normal and pathological states of the patient, and its fundamental goal is to increase the objectivity of clinical analysis and to allow a more extensive recording of a subjects' symptoms and behavioral traits (above all, those that are specifically definable) over different time intervals. Moreover, the 
aim of the rating scale is to reduce subjectivity in order to obtain data that can be analyzed and compared with other common data. ${ }^{11,12}$

In the current music therapy literature, there is a paucity of coded systems of measurement. ${ }^{13,14}$ The purpose of this study is to present a tool - the Music Therapy Rating Scale (MTRS) - which could be used to monitor what happens during clinical sessions of music therapy, as well as to provide help in the analysis of the gathered data.

In particular, the tool presented here gives the possibility of observing and assessing the non-verbal relationship (NVR) and the sonorous-musical relationship (SMR) as part of the music therapy sessions. MTRS could provide useful support in the evaluation of a music therapy process (based on the interaction between the patient and the music therapist) both in clinical practice and for research purposes.

The MTRS measures the intensity of the relationships (NVR and SMR), creating the possibility to be aware of trends not only in the case of a single session, but also over the whole course of music therapy treatment.

Table 1 indicates the level of relationship that can be obtained in reference to NVR and SMR. Level 0 coincides with the absence of those components that indicate contact between the music therapist and the patient from the observer's point of view. Levels 1 to 4, on the other hand, show evidence of elements indicating the presence of shared emotions, ${ }^{7}$ that is, different ways of interaction between the music therapist and the patient. As far as the NVR is concerned, it is made up of different levels, starting from a face-to-face perspective (level 1), that gradually entails

Table I Degrees of NVR and SMR

\begin{tabular}{|c|c|}
\hline Non-verbal relationship (NVR) & $\begin{array}{l}\text { Sonorous-musical } \\
\text { relationship (SMR) }\end{array}$ \\
\hline $\begin{array}{l}0=\text { physical distance, absence of } \\
\text { looking at each other and/or physical } \\
\text { withdrawal from each other }\end{array}$ & $\begin{array}{l}0=\text { absence of sonorous- } \\
\text { musical production }\end{array}$ \\
\hline $\begin{array}{l}\text { I = physical distance, looking } \\
\text { at each other }\end{array}$ & $\begin{array}{l}\text { I = individual sonorous- } \\
\text { musical production }\end{array}$ \\
\hline $\begin{array}{l}2 \text { = physical closeness, absence } \\
\text { of looking at each other and/or } \\
\text { physical withdrawal from each other }\end{array}$ & $\begin{array}{l}2 \text { = disattuned sonorous- } \\
\text { musical production }\end{array}$ \\
\hline $\begin{array}{l}3 \text { = physical closeness, reciprocity } \\
\text { of bearing/front position and/or } \\
\text { looking at each other }\end{array}$ & $\begin{array}{l}3 \text { = attuned sonorous- } \\
\text { musical production, staticity, } \\
\text { imitation }\end{array}$ \\
\hline $\begin{array}{l}4=\text { reciprocity of bearing/front } \\
\text { position, looking at each other, } \\
\text { smile/expressive and/or body } \\
\text { involvement }\end{array}$ & $\begin{array}{l}4=\text { attuned sonorous- } \\
\text { musical production, dynamism, } \\
\text { variations of the sonorous- } \\
\text { music parameters and structure }\end{array}$ \\
\hline
\end{tabular}

physical closeness (level 2), reciprocity (level 3), encouraged by the maintaining of the face-to-face contact between the music therapist and the patient during the session, and finally emotional involvement through facial expression and/or physical closeness (level 4). The four levels of the SMR are the following: the individual production of music by the patient with no communication with the music therapist (level 1), discordant sonorous music production between the music therapist and the patient (level 2), attuned production between the music therapist and the patient on a formal level (level 3), and finally, attuned production of music with an emotional involvement between the music therapist and the patient by means of variations of musical parameters and by a high dynamism (level 4).

The relationship between NVR and SMR is assessed by the observer at intervals of 15 seconds each. The observer takes note of the highest levels of NVR and SMR during each 15-second period. Through the software proposed in the present study, the data of MTRS are backed up by a digital scheme that automatically calculates the average per minute of the NVR and SMR and the sum of both (Figure 1).

Moreover, the computer program automatically makes a graph that records NVR, SMR, and NVR + SMR during the session (Figure 2).

Although the MTRS can be used and recorded during a session (eg, via observation behind a one-way mirror), it is advised to observe the sessions on video.

\section{Method}

\section{Participants}

The data of seven patients (four boys and three girls; mean age $=6.28$ years; see Table 2 ), for whom the diagnosis of Pervasive Developmental Disorders ${ }^{15}$ was proposed, were examined. More specifically, within this clinical picture, for two boys (cases 1 and 6) Autistic Disorder was diagnosed; for one girl (case 7) Rett's Disorder; for two girls (cases 3 and 5) a Pervasive Developmental Disorder Not Otherwise Specified; for one boy (case 2) Childhood Disintegrative Disorder; and for one boy (case 4) Asperger's Disorder. Parents of these children gave their approval for the use of the data in our research project.

\section{Procedure}

Two fixed video cameras, positioned in two corners of the room in which the music therapy session took place, videotaped the patient-therapist groups. Two couples of music therapists (with training in the intersubjective music therapy 


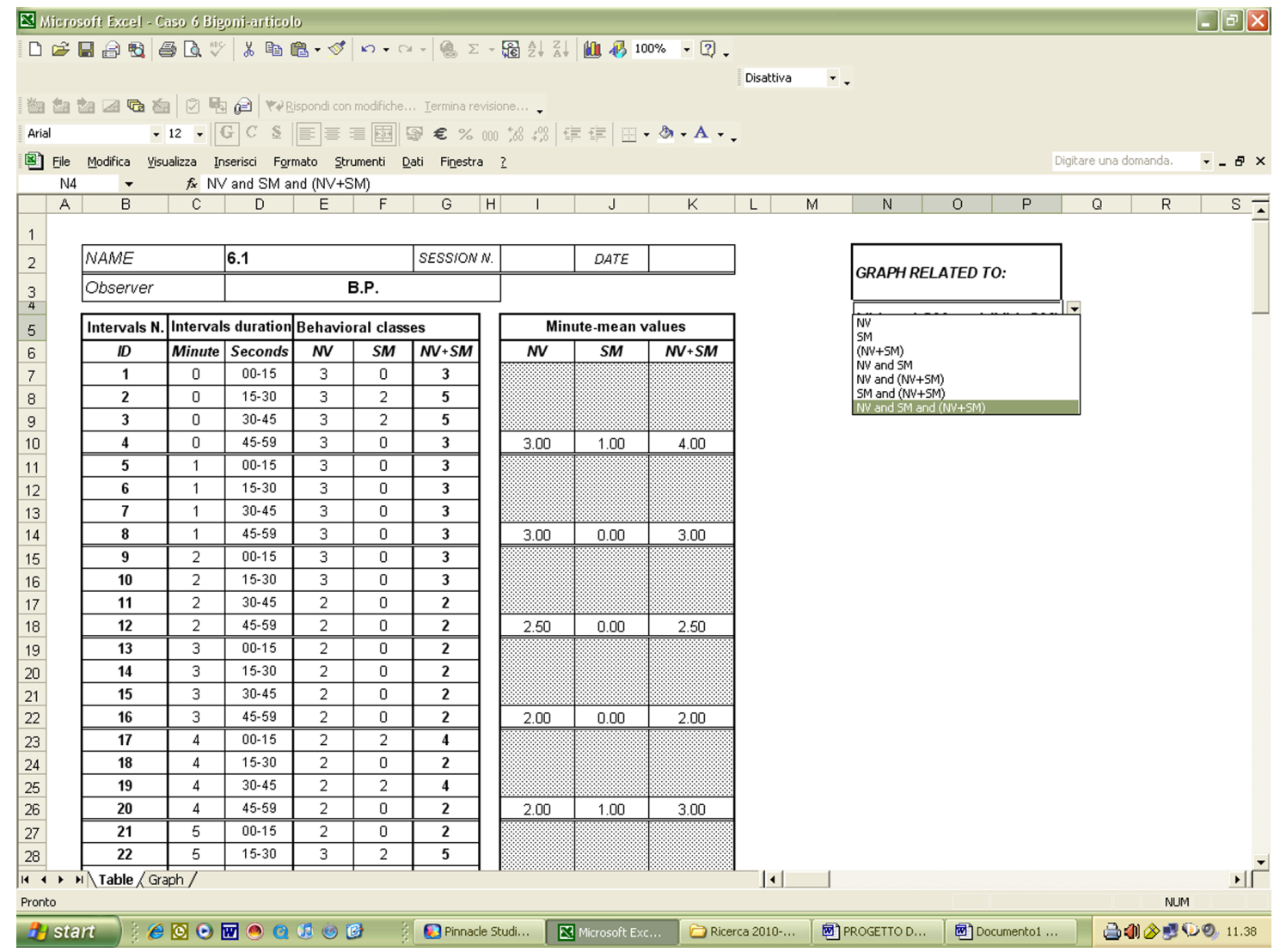

Figure I Example of scheme of the MTRS (electronic format).

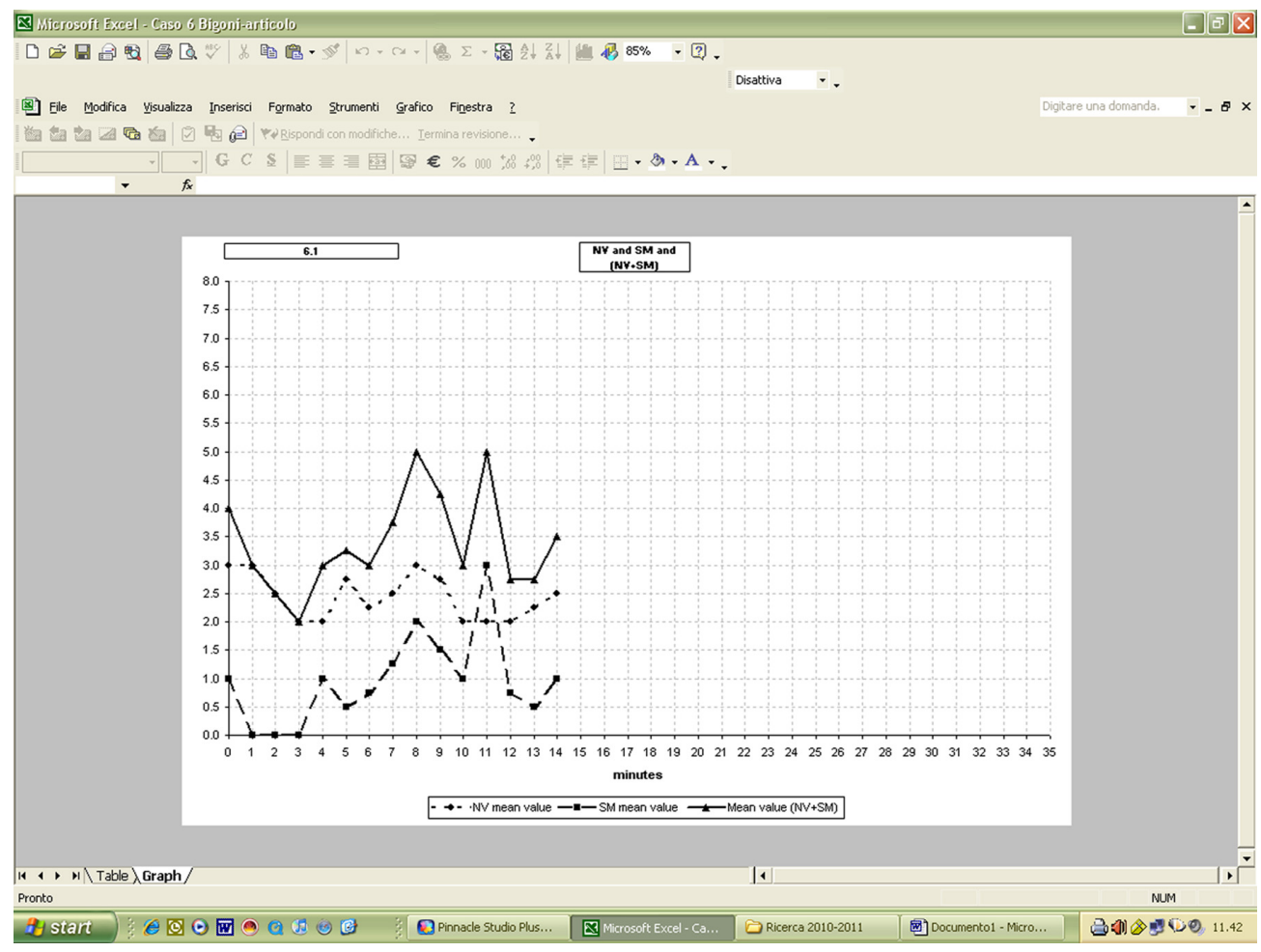

Figure 2 Example of graph of the MTRS (electronic format). 
Table 2 Spearman's rho coefficient for each behavioural class (NVR, SMR), by subjects

\begin{tabular}{lllll}
\hline Case & Sex & $\begin{array}{l}\text { Age } \\
(\mathbf{y r} .)\end{array}$ & $\begin{array}{l}\text { Non-verbal } \\
\text { relationship } \\
\text { (NVR) }\end{array}$ & $\begin{array}{l}\text { Sonorous-musical } \\
\text { relationship } \\
\text { (SMR) }\end{array}$ \\
\hline 1 & Male & 6 & 0.78 & 0.67 \\
2 & Male & 3 & 0.54 & 0.77 \\
3 & Female & 7 & 0.87 & 0.74 \\
4 & Male & 5 & 0.93 & 0.74 \\
5 & Female & 6 & 0.61 & 0.82 \\
6 & Male & 7 & 0.55 & 0.70 \\
7 & Female & 10 & 0.64 & 0.93 \\
Mean & & & 0.70 & 0.77 \\
\hline
\end{tabular}

approach) blindly coded 15 minutes in the middle of the videotape concerning the first active music therapy session of each patient. Each 15-second interval was assessed independently by each couple and scored by a 5-point scale on the NVR and SMR scales, according to the MTRS criteria.

\section{Analysis}

Given the nature of the data, consisting of ratings given by two observers, the evaluation of the agreement between the two pairs of observers was carried out through Spearman's Rho coefficient, which transforms the original scores into ranks.

\section{Results}

Due to the considerable heterogeneity among patients, the agreement index was carried out for each case (Table 2). According to Fleiss ${ }^{16}$ taxonomy of reliability levels, the Spearman's rho coefficients obtained for SMR were acceptable in $86 \%$ of cases (mean $\rho=0.77$ ), while for NVR they were acceptable only in $43 \%$ of cases (mean $\rho=0.70$ ).

\section{Discussion}

The data showed significant evidence of agreement between the observers, and the MTRS can be considered a useful tool in the monitoring process over single sessions and the whole treatment. In particular, the MTRS portrays the development of the relationship between music therapist and patient.

Our interpretation of progress in music therapy sessions is grounded on the intersubjective approach. ${ }^{7-10}$ In particular, a score of 7 or 8 (NVR + SMR) could indicate a high level of relationship and interaction, characterized by sonorousmusical and emotional involvement. In our opinion it is a moment of affect attunement ${ }^{7}$ and contact - moment of meeting ${ }^{8}$ - between the patient and music therapist. A score $(\mathrm{NVR}+\mathrm{SMR})$ of 6 indicates moderate attunement and effective contact, characterized by partial sonorous-musical and emotional involvement; a score (NVR + SMR) between 1 and 5 indicates a low level of contact between the patient and the music therapist, characterized by an absence of emotional interaction, a static condition, and imitative and unchanged music production. A score of 0 indicates an absence of any relationship in either NVR or SMR. In this way, it is possible to observe different levels of relationship and interaction between the patient and music therapist, as the rating scale was intended for. ${ }^{11,12}$

As to the Music Therapy Coding Scheme (MTCS) ${ }^{5}$ and the Music Therapy Check List (MTCL), ${ }^{6}$ the MTRS is an easier tool to use and more effective in describing and distinguishing the main aspects of the intersubjective relationship (patient/music therapist). The MTRS' characteristics allow the quantification of this relationship and the assessment of trends.

The use of our software allows us to monitor in real time the data gathered by MTRS and to evaluate both the NVR and SMR increase and the music therapy's outcome. This tool doesn't require more time than that necessary for session observation. To use it correctly, it is advisable that observers, who already have a basic knowledge of music therapy, undergo a brief training period on top of this. In our opinion, these results must be taken into account for future applications with empirical approach in clinical context. ${ }^{4}$

From the observed samples it is evident that continuous movements in the music therapy setting sometimes characterize the patient's behavior, which is a potential limitation. These results show a particular difficulty of observers in coding NVR, probably due to the high frequency of position changes observable in the young patients in this work. However, the good level of reliability in SMR coding is quite encouraging, as this scale assesses the specific quality of relationship expressed by musical production, which can be considered the peculiar element that differentiates music therapy from the other therapeutic approaches. However, we obtained positive results, even if further applications will be necessary in the future to confirm the encouraging results of the application of MTRS.

\section{Acknowledgment}

Our thanks to the music therapists Alessandra Balagna, Elena Bonalumi, Marta Gianotti, and Elena Rossomanno for processing the data.

\section{Disclosure}

The authors report no conflicts of interest in this work. 


\section{References}

1. Kernberg OF, Burnstein E, Coyne L, Apfelbaum A, Horowitz L, Voth H. Psychotherapy and psychoanalysis: final report of the menninger foundation's psychotherapy research project. Bull Menninger Clin. 1972;36:1-275.

2. Wallerstein RS. Forty-two lives in treatment: a study of psychoanalysis and psychotherapy. New York: Guilford Press; 1986.

3. Freedheim DK. History of psychotherapy: a century of change. Washington, DC: American Psychological Association (APA); 1992.

4. Fonagy P, Target M, Cottrell D, Phillips J, Kurtz Z. What works for whom? A critical review of treatments for children and adolescents. New York: Guilford; 2002.

5. Raglio A, Traficante D, Oasi, O. A coding scheme for the evaluation of the relationship in music therapy sessions. Psychol Rep. 2006;99: 85-90.

6. Raglio A, Traficante D, Oasi O. Comparison of music therapy coding scheme with the Music Therapy Checklist. Psychol Rep. 2007;101: 875-880.

7. Stern D. The interpersonal world of the infant. New York: Basic Book; 1985.

8. Stern D. The present moment in psychotherapy and everyday life. London, UK: Norton and Company Ltd; 2004.
9. Tronick EZ. Emotions and emotional communication in infants. $A m$ Psychol.1989;44:112-119.

10. Trevarthen C, Aitken KJ. Infant intersubjectivity: research, theory, and clinical applications. J Child Psychol Psychiatry. 2001;1:3-48.

11. Conti L. Collection of evaluation instruments in psychiatry. Florence, Italy: Società Editrice Europea; 1999. [Italian].

12. Conti M, Luzzati D. Inventory and Rating Scale. In Del Corno F, Lang M. editors. Elements of Clinical Psychology. Milan, Italy: Franco Angeli; 2005. [Italian].

13. Wigram T. Improvisation. Methods and techniques for music therapy clinicians, educators, and students. London, UK: Jessica Publishers; 2004.

14. Raglio A. Music therapy and evidence based approach: from clinical application to research. Milan, Italy: Franco Angeli; 2008. [Italian].

15. American Psychiatric Association. Diagnostic and statistical manual of mental disorders DSM-IV-TR. (Text Rev.) Washington, DC; 2000.

16. Fleiss JL. Statistical methods for rates and proportions. New York: Wiley; 1981.
Pragmatic and Observational Research

\section{Publish your work in this journal}

Pragmatic and Observational Research is an international, peer-reviewed, open access journal that publishes data from studies designed to reflect more closely medical interventions in real-world clinical practice compared with classical randomized controlled trials (RCTs). The manuscript management system is completely online and includes a very quick and fair peer-review

Submit your manuscript here: http://www.dovepress.com/pragmatic-and-observational-research-journal

\section{Dovepress}

system. Visit http://www.dovepress.com/testimonials.php to read real quotes from published authors. 